58 of the Mental Health Act 1983, among others for clozapine. He was experiencing hypersalivation as a side-effect so was prescribed hyoscine hydrobromide. It was not thought necessary to include this on the Form 38 as hyoscine is not a psychotropic drug. The Commissioner, however, stated that the hyoscine was not authorised, meaning the medication had been unlawfully administered, and the Avon and Wiltshire Mental Health Partnership NHS Trust had to advise the patient about his right to seek legal advice.

Hyoscine appears twice in the British National Formulary, in the chapter on the central nervous system under 'Drugs used in nausea and vertigo' and in the chapter on anaesthesia under 'Antimuscarinic drugs'. Hyoscine is not classified under 'Antimuscarinic drugs used in parkinsonism'. Antimuscarinic drugs used for anaesthesia is quite distinct from 'Antimuscarinic drugs used in parkinsonism' We do regard the latter as needing to be documented on the legal paperwork, such as precyclidine, because of an accepted recognition of good practice. Is it now the case that for any side-effect caused by psychotropic medication that is being treated by drugs, these drugs need to be listed on Forms 38/39? If so, should our patient's senna and metformin be listed as well, as the constipation and diabetes he has is likely (but of course not necessarily) to be a result of the clozapine?

BMJ PUBLISHING GROUP \& RPS PUBLISHING (2007) British National Formulary 54. BMJ Publishing Group \& RPS Publishing.

Vichal Woochit Specialty Registrar year 4 Wickham Unit, Blackberry Hill, Bristol BS16 1ED, email: vichal.woochit@awp.nhs.uk,

Syed Husain Consultant Forensic Psychiatrist Wickham Unit, Blackberry Hill, Bristol

doi: $10.1192 / p b .32 .5 .196 b$

\section{New exam structure - too much too soon?}

The last examinations in the 'old format' have now finished, making the editorial and commentaries on 'The long case is dead' very timely (Ashurst, 2007; Benning \& Broadhurst, 2007; Tyrer, 2007). In addition, psychiatric training is undergoing significant change, particularly following the difficulties associated with Medical Training Application System, and Modernising Medical Careers.

With the move towards competencybased curricula, it is important to reassess the way that trainees are assessed. Objective Structured Clinical Examinations (OSCEs) are increasingly used to assess medical students instead of the traditional long and short cases. Long cases have been used in examinations since the 1970s and while standardisation of OSCEs is easier, each station provides only a snapshot of a candidate's performance.

Workplace-based assessments are a useful addition in the assessment of trainees' competences and will now be the main method of evaluating their ability to perform a full comprehensive clinical assessment. However, these are new tools for both trainees and supervisors and it will take time and further development before they become a reliable method of assessment.

Many trainees have prepared for one examination format only to be forced into a new system, while the transitional arrangements mean that some aspects of the curriculum will not be tested in those who have obtained Part 1 and are exempt from Paper 2. Neither of these situations is ideal. An overlap between the old and new examination formats may have allowed an easier transition to a new way of working for trainees and help avoid the significant anxiety experienced by those affected by the changes

ASHURST, P. (2007) On listening to the patient: Commentary on... The long case is dead. Psychiatric Bulletin, 31, 446-447.

BENNING,T. \& BROADHURST, M. (2007) The long case is dead - long live the long case. Loss of the MRCPsych long case and holism in psychiatry. Psychiatric Bulletin, 31, 441-443.

TYRER, S. (2007) Non mors praematura: Commentary on... The long case is dead. Psychiatric Bulletin, 31, 447-449.

Elena Baker-Glenn Specialist Trainee Year 3, Queen's Medical Centre, Nottingham NG7 2UH, email: elenabakerglenn@yahoo.co.uk

doi: 10.1192/pb.32.5.197

\section{Forensic psychiatry and general psychiatry: re-examining the relationship}

I have heard the essence of the Turner \& Salter article (Psychiatric Bulletin, January 2008, 32, 2-6) before but repetition does not produce enlightenment. At root, it is an attack on a branch of medicine that the authors do not seem to approve of. That is odd: I cannot think of any other branch of medicine which attracts this kind of negativity.

As John O'Grady has explained in his reply (Psychiatric Bulletin, January 2008, $32,6-7)$, there are many reasons why forensic psychiatry has developed. Nevertheless, one omission from the debate so far, which is surprising in view of one of Turner's other strong interests, is history. It is easy to trace the development of forensic psychiatry from about 1814 as a response to a growing awareness of the social and psychiatric problems presented by many offenders with mental disorders.
The growing specialty of psychiatry was expected to take on this important group of patients. From the earliest years of this period, until the present day, general psychiatrists have tried to resist this expectation. Personally, I think that is entirely reasonable, as such patients require special facilities and special skills. However, it is unreasonable to complain when others take up the challenge instead.

For many years there were very few who took an interest in this work and very few facilities for such patients. As pressure from general psychiatrists, prisons and mental hospitals (which gradually declined in number) increased, so did the demand for special skills. With that, overcrowding in the first forensic psychiatry hospitals, the special hospitals, also increased.

The natural professional response to this was for psychiatrists, with the unusual special interest in offenders with mental disorders, to get together to discuss matters, especially clinical matters, of mutual interest. A forensic psychiatry subcommittee of the Royal MedicoPsychological Association (the forerunner to the Royal College of Psychiatrists) was formed in 1963. This became a section of forensic psychiatry when the Royal College of Psychiatrists began in 1971, and eventually, in 1997, the Faculty of Forensic Psychiatry. The clinical meetings of this developing organisation have attracted an increasing number of College members. Any psychiatrist is welcome to attend the meetings and general psychiatrists, as Turner and Salter know well, are especially welcome. We even invite them to express their negative views in debate!

Perhaps there is a hidden agenda to all this. Speculation is usually unhelpful, so I will not indulge. Maybe I can, however, entice Trevor Turner to spell out more closely what ails him. Does he have the same allergy to other specialties, and if not, then why not? I think I can speak for the majority of members of the Forensic Psychiatry faculty when I say that they are always interested to learn new ways of working and to serve patients' interests better.

John Gunn Former Chairman, Faculty of Forensic Psychiatry, and Emeritus Professor of Forensic Psychiatry, Institute of Psychiatry, King's College London

doi: $10.1192 / \mathrm{pb} .32 .5 .197 \mathrm{a}$

Trainees' views on service user and carer involvement in training: a perspective from the West Midlands

A survey similar to Babu et al (Psychiatric Bulletin, January 2008, 32, 28-31) was 
conducted in the West Midlands a year after it became mandatory to involve users and carers in psychiatric training. Completed questionnaires were received from 180 trainees and included specialist registrars from all specialties and senior house officers from all four rotations. A greater percentage of trainees $(64 \% \mathrm{~V}$. $47 \%$ in Babu et al's survey) were aware of the College requirement for user and carer involvement in training. As with Babu et al's survey, the most common setting was during case presentations (77\%). As many as $61 \%$ of senior house officers had experienced user and carer involvement in their Member of the Royal College of Psychiatrists' academic programme compared with only $23 \%$ of specialist registrars.

The majority wanted users and carers to share their experiences and perspectives ( $82 \%)$ and to give feedback about their ability, attitudes and skills (70\%). This was less so for involvement in planning teaching programmes (22\%) and in selection of trainees onto training schemes (17\%). This may be a reflection of the same reservations highlighted in Babu et al's survey. Livingston \& Cooper's (2004) recommendation for training and support to users and carers would be essential in addressing these concerns. The introduction and implementation of this major component in training requires balancing the sensitivities and needs of both service users and trainees. Drawing from the experiences of other training schemes and the results of further research and audit will be an integral part in furthering this area of training.

LIVINGSTON, G. \& COOPER, C. (2004) User and carer involvement in mental health training. Advances in Psychiatric Treatment, 10, 85-92.

*Amitav Narula Specialist Registrar in Genera Adult Psychiatry, Birmingham and Solihull Mental HealthTrust, Small Heath Health Centre, Chapman Road, Birmingham B10 OPG, email: samant@narulas. freeserve.co.uk, Elizabeth Furlong Specialist Registrar in General Adult Psychiatry, Birmingham and Solihull Mental HealthTrust, Nicole Karen Fung Specialist Registrar in Child and Adolescent Psychiatry, Parkview Clinic, Moseley

doi: $10.1192 / p b .32 .5 .197 b$

\section{Whose line is it anyway?}

There is an assumption (by psychiatrists) that all physical care is the territory of the general practitioner (Tarrant, 2006), whereas psychiatrists tend to focus on arranging appropriate monitoring of medications that they are prescribing. However, there is a growing awareness of the global physical health needs of those with severe and enduring mental illnesses. This is confounded by the current lack of a clear consensus from multiple and differing guidelines on the necessary monitoring for both primary and secondary care.

Patients with severe mental illness, such as schizophrenia, bipolar disorder and depression, are said to lose 25 years or more of life expectancy (Newcomer \& Hennekens, 2007); the majority due to cardiovascular disease (CVD). It is not surprising then that psychiatric patients tend to have a higher prevalence of independent predictors of CVD including smoking, hypertension, obesity, a sedentary lifestyle and hyperlipidaemia - an 'inherent' predisposition to CVD. However, there seems to be some disparity in prevention efforts for cardiovascular mortlality when comparing individuals with severe menal illness and the general population. In a correspondence letter to the Bulletin, Dr Mohd (rightly) expresses his concern that action needs to be taken when any results or measurements are found to be abnormal. Results are often duly communicated to general practitioners by letter but may easily be overlooked. He goes on to suggest that we (psychiatrists) should initiate anti-lipid treatment ourselves (Mohd, 2006)

Yet, according to the most recent Joint British Societies' guidelines, the indications to commence antilipid therapy are quite clear: 'at high risk' - atherosclerotic disease, diabetes or a high total CVD risk $>20 \%$ (British Cardiac Society et al, 2005). However, in patients with severe mental illness, the total CVD risk is often below $20 \%$ for that specific period of time

Most research has focused on the impact of some antipsychotic medication being linked to quite marked hypercholesterolaemia (Correll et al, 2007). The reasonable deduction is that these patients can be offered an alternative, less lipid-inducing antipsychotic and/ or lifestyle changes. Lifestyle advice is often difficult to implement on the background of ongoing and enduring psychiatric illness given that use of healthcare services often decreases after the onset of a psychiatric disorder.

Some may argue that cardiovascular risk in patients who are stable on regular antipsychotic medication should be treated the same as anybody else with the same risk factors. However, given that patients with severe and enduring mental illness (with/without antipsychotic medication) are 'inherently' predisposed to CVD, would it be sensible just to wait until the risk passes the $20 \%$ threshold? Or is there a 'missed opportunity' here.

Closer attention is needed, first, to the choice of psychotropic drug treatment and second, more aggressive in-hospital use of monitoring and interventions to identify and reduce risk. In this targetdriven culture, we often assign arbitrary values to continuous and often fluctuating biological variables. Perhaps we ought to abandon the notion of 'one threshold fits all'; instead, use our clinical judgment to initiate treatment based on overall risk.

BRITISH CARDIAC SOCIETY, BRITISH HYPERTENSION SOCIETY, DIABETESUK, et al (2005) JBS2: Joint British Societies' Guidelines on Prevention of Cardiovascular Disease in Clinical Practice. Heart, 91, v1-v52.

CORRELL, C. U., HARRIS, J. I., PANTALEONMOYA, R. A. (2007) Low-density lipoprotein cholesterol in patients treated with atypical antipsychotics: missed targets and lost opportunities. Schizophrenia Research, 92 103-107.

MOHD, K. (2006) Monitoring the physical health of psychiatric patients on psychotropic drugs. Psychiatric Bulletin, 30, 468-469.

NEWCOMER, J. \& HENNEKENS, C. (2007) Severe mental illness and risk of cardiovascular disease. JAMA, 298, 1794-1796.

TARRANT, C. (2006) Blood glucose. Psychiatric Bulletin, 30, 287-288.

Oliver van Hecke ST2 General PractitionerTrainee, c/o Department of Psychiatry, Murray Royal Hospital, Perth PH2 7BH, email: ovanhecke@nhs.net

doi: 10.1192/pb.32.5.198 